\title{
BREVE COMPARACIÓN ENTRE EL RÉGIMEN NORMATIVO DE COLABORACIÓN DEL ESTADO PERUANO CON LA IGLESIA CATÓLICA Y EL APLICABLE AL RESTO DE CONFESIONES RELIGIOSAS
}

\author{
DIEGO ALONSO ESTELA VARGAS
}

\begin{abstract}
Resumen
El presente trabajo realiza un breve análisis comparativo entre el Acuerdo suscrito entre la Santa Sede y la República del Perú de 1980, del cual se desprende el marco jurídico de la cooperación proporcionada a la Iglesia Católica; y la Ley de Libertad Religiosa y su reglamento vigente, que regulan ciertos aspectos colaborativos referidos al resto de confesiones en el país.

Palabras clave: Cooperación o colaboración, Estado peruano, confesiones religiosas, Iglesia católica, Acuerdo de 1980 entre el Perú y la Santa Sede, Ley de Libertad Religiosa, personalidad jurídica y registro, asistencia religiosa, régimen fiscal.
\end{abstract}

\begin{abstract}
This paper makes a brief comparative analysis between the Agreement signed between the Holy See and the Republic of Peru in 1980, which shows the legal framework for the cooperation provided to the Catholic Church; and the Religious Freedom Act and its current regulations, which regulate certain collaborative aspects concerning the other religious confessions in the country.

Keywords: Cooperation or collaboration, Peruvian State, religious confessions, Catholic Church, Agreement of 1980 between Peru and the Holy See, Religious Freedom Act, legal personality and registration, religious assistance, tax regime.
\end{abstract}

DOI: 10.7764/RLDR.9.106

\section{INTRODUCCIÓN}

El principio de cooperación o colaboración, cuyo origen se deriva del Derecho Eclesiástico, es aquel que ordena las actuaciones del Estado destinadas a facilitar y promover

\footnotetext{
${ }^{1}$ Abogado por la Pontificia Universidad Católica del Perú (PUCP). Dedicado a la investigación del Derecho Eclesiástico. E-mail: diegoestelav@hotmail.com.
} 
Diego Alonso Estela Vargas: Breve comparación entre el régimen normativo de colaboración del Estado peruano con la iglesia católica y el aplicable al resto de confesiones religiosas.

las manifestaciones de libertad religiosa colectiva mediante disposiciones jurídicas de colaboración entre las confesiones y el Estado.

En el Perú, dicha cooperación está regulada por un sistema de normas jurídicas, el cual encuentra su fundamento en el artículo $50^{\circ}$ de la Constitución ${ }^{2}$, representando el origen del que se derivan las relaciones de colaboración entre el Estado y los grupos religiosos, lo que ocurre a través de regímenes diferenciados: por un lado, con la Iglesia católica y, por otro, con el resto de confesiones.

En tal sentido, es elemento del presente trabajo el análisis comparativo entre el Acuerdo suscrito entre la Santa Sede y la República del Perú de 1980, del cual se desprende el marco jurídico de la cooperación proporcionada a la Iglesia Católica; y la Ley de Libertad Religiosa y su reglamento vigente, que regulan ciertos aspectos colaborativos referidos al resto de confesiones en el país.

Por razones de extensión, este artículo se limitará a desarrollar los temas relacionados a la personalidad jurídica y registro de las entidades religiosas; su financiación, exoneraciones y beneficios tributarios que les son aplicables; y la asistencia religiosa; debido a que son tópicos muy discutidos por la doctrina nacional.

\section{El Acuerdo suscrito entre la Iglesia Católica y el Estado peruano}

El Acuerdo entre la Santa Sede y la República del Perú, suscrito en 1980, tiene 22 artículos o cláusulas que regulan temas que afectan a ambas en sus relaciones bilaterales: personalidad jurídica, jurisdicción, financiación, exoneraciones y beneficios tributarios, asistencia religiosa, educación, etc.

Para ser más precisos, este tratado internacional reconoce a la Iglesia católica personalidad jurídica de carácter público, así como plena capacidad y libertad en todo lo relativo a la adquisición y disposición de bienes, y a la recepción de ayudas económicas del

\footnotetext{
${ }^{2}$ Artículo $50^{\circ}$. - Dentro de un régimen de independencia y autonomía, el Estado reconoce a la Iglesia Católica como elemento importante en la formación histórica, cultural y moral del Perú, y le presta su colaboración. El Estado respeta otras confesiones y puede establecer formas de colaboración con ellas.
} 
exterior. Además, trata con cuidado la cuestión de los capellanes castrenses, reconociendo, de la mano con ello, el compromiso de una adecuada asistencia religiosa para el personal católico de las Fuerzas Armadas y la Policía Nacional, así como para sus fieles internados en centros hospitalarios, tutelares y penitenciarios del Estado. Adicionalmente, hace mucho énfasis en el tema educativo, pues establece que la Iglesia tiene plena libertad para establecer centros educativos de todo nivel de conformidad con la legislación peruana.

\subsection{Personalidad jurídica y registro}

Los artículos II, III y IV del Acuerdo tratan sobre la personalidad jurídica de carácter público que otorga el Estado peruano a la Iglesia católica, a la Conferencia Episcopal Peruana, a los arzobispados, obispados, prelaturas, vicariatos apostólicos existentes y los que posteriormente pueda crear la Santa Sede, a los cabildos eclesiásticos, los seminarios diocesanos, y a las parroquias y divisiones dependientes de aquellas. Siendo así, las citadas disposiciones se expresan de la siguiente manera:

Artículo II.- La Iglesia Católica en el Perú continúa gozando de la personería jurídica de carácter público, con plena capacidad y libertad para la adquisición y disposición de bienes, así como para recibir ayudas del exterior.

Artículo III.- Gozan también de tal personería y capacidad jurídica, la Conferencia Episcopal Peruana, los Arzobispados, Obispados, Prelaturas y Vicariatos Apostólicos existentes ${ }^{3}$, y los que, posteriormente, pueda crear la Santa Sede.

Artículo IV.- La personería y capacidad jurídica de tales Jurisdicciones Eclesiásticas comprenden también a los Cabildos Eclesiásticos, a los Seminarios Diocesanos, y a las Parroquias y Misiones dependientes de aquellas.

Como se observa, el artículo II afirma que la Iglesia continúa gozando de la personalidad jurídica de carácter público, la cual también se extiende a sus entidades

\footnotetext{
${ }^{3}$ Antes de la firma del Acuerdo de 1980, el Decreto Supremo N019-78-PM ya precisaba que la Iglesia católica en el Perú gozaba de personería jurídica en el ámbito del Derecho Público interno; así como la Conferencia Episcopal Peruana, los Arzobispados, Obispados, Prelaturas y Vicariatos Apostólicos, y los Cabildos Eclesiásticos, Seminarios Diocesanos, Parroquias y Misiones que dependían de aquellos.
} 
Diego Alonso Estela Vargas: Breve comparación entre el régimen normativo de colaboración del Estado peruano con la iglesia católica y el aplicable al resto de confesiones religiosas.

eclesiásticas derivadas, tal como se prescribe en los artículos III y IV ${ }^{4}$. A nuestro juicio, esto significa la subsistencia de un reconocimiento ya existente que, a partir de este Acuerdo, adquirió rango constitucional.

El tema de la personalidad jurídica pública de la Iglesia en el Perú es sumamente polémico. En virtud de ello, se discute mucho su naturaleza jurídica, pues podría entenderse que se aparta de lo que ella misma proclama: independencia y autonomía del Estado. Sumado a ello, el debate se hace más controversial si consideramos que, de acuerdo a ley, las confesiones religiosas no católicas sólo pueden adquirir personalidad jurídica privada o civil.

Sobre el particular, Revilla cree que la naturaleza atribuida tanto a la Iglesia católica, como a sus entes eclesiásticos derivados que conforman su estructura en el Perú, no es la mejor, porque su asimilación al Estado, de alguna manera, la configura como una confesión privilegiada en vista de los beneficios y tratos preferenciales que tienen sus autoridades, los cuales surgen, justamente, a raíz de su situación de persona jurídica pública. En tal sentido, pone en tela de juicio la no confusión entre la esfera pública y la religiosa establecida en el Perú desde la Constitución de 1979 (2017, p. 72).

Como está dispuesto en el Acuerdo, el reconocimiento de la personalidad jurídica de la Iglesia católica se extiende a toda entidad religiosa que sea creada por la Santa Sede. Así, no se sujetarán a ninguna calificación registral estatal para ser consideradas como entes religiosos, sino que, por su calificación canónica, pasarán a gozar automáticamente del estatus reconocido a la Iglesia en el Acuerdo.

Al proceder de esta manera, Huaco (2010) considera que, inevitablemente, se introducen elementos discriminatorios en las políticas religiosas de los Estados, ya que éstos luego deben emitir normas legales unilaterales para regular el mismo o similar reconocimiento a las agrupaciones religiosas minoritarias (p.42). De esta forma, para este autor, no existe igualdad en el acceso, ni en la calificación, del reconocimiento de la

\footnotetext{
${ }^{4}$ Cabe recordar que, la personalidad jurídica de carácter público atribuida tanto a la Iglesia católica, como a algunas de sus instituciones, no le corresponde a la Santa Sede, pues ésta goza de personalidad jurídica internacional garantizada por instrumentos jurídicos y por la comunidad internacional.
} 
ISSN 0719-7160

personalidad jurídica eclesiástica, ni tampoco en la naturaleza de dicho reconocimiento, ya que a las agrupaciones no católicas en el Perú sólo se les reconoce personería de derecho privado luego de satisfacer una serie de condicionamientos legales que el Estado impone en función del cuidado del orden público.

Desde otro punto de vista, Fernández (1986) declara que la Iglesia católica es un sujeto de derecho público de carácter supranacional, cuya actividad jurídica en el Perú no requiere de una ley propia para su creación, sino que tal actividad le está reconocida por el ordenamiento jurídico nacional en cuanto se trata de un ente jurídico supranacional, en virtud del Acuerdo de 1980 (p.200). Bajo este criterio, se entiende que el reconocimiento de la personería jurídica pública de la Iglesia sólo sirve para que ésta actúe, válida y legalmente, en el ordenamiento jurídico peruano (Rodríguez, 2006, p. 210).

Por tal razón, Flores (2007) afirma que la Conferencia Episcopal Peruana, los Arzobispados, Obispados, Prelaturas y Vicariatos Apostólicos; así como los Cabildos Eclesiásticos, los Seminarios Diocesanos, y las Parroquias y Misiones, son jurisdicciones de la Iglesia católica que tienen naturaleza jurídica canónica, por lo que no son personas jurídicas nacionales o peruanas. En tal sentido, a éstas no se les aplica las normas del Código Civil, ni pueden ser concebidas como organizaciones no gubernamentales. Adicionalmente, como gozan también de personería de carácter público para poder realizar actos jurídicos válidos, no requieren inscribirse en los Registros Públicos (pp. 69-70).

Por otro lado, en el artículo IX del Acuerdo, se dispone la personalidad jurídica civil, conforme al Código Civil peruano, de las órdenes, congregaciones religiosas y los institutos seculares, respetándose su régimen canónico interno, de la siguiente manera:

Artículo IX.- Las Órdenes y Congregaciones Religiosas y los Institutos Seculares podrán organizarse como Asociaciones, conforme al Código Civil Peruano, respetándose su régimen canónico interno.

El reconocimiento explícito de la personalidad pública de la Iglesia en el Perú se contrasta nítidamente con aquel que se hace a algunas de sus entidades como las órdenes, congregaciones religiosas e institutos seculares, quienes, manteniendo su régimen interno de acuerdo al Derecho Canónico, pueden erigirse, a efectos civiles, adoptando la forma de 
Diego Alonso Estela Vargas: Breve comparación entre el régimen normativo de colaboración del Estado peruano con la iglesia católica y el aplicable al resto de confesiones religiosas.

asociaciones de acuerdo al Código Civil. En otras palabras, estas instituciones pueden adoptar la figura de asociación para ser reconocida su personalidad privada, a fin de actuar dentro de la esfera jurídica del Estado peruano.

De acuerdo con ello, habría que tener cuidado de no malinterpretar esta disposición sosteniendo que tales instituciones son asociaciones civiles sin fines de lucro, o que deben convertirse en ellas por medio de una reconstitución. De lo contrario, se caería en el absurdo de una entidad bicéfala con una personalidad y unos órganos en el ámbito canónico, y otra personalidad y otros órganos, no identificables con los primeros, en el plano civil (Valderrama,1998, pp. 19-20).

Finalmente, acerca del registro, se expidió la Resolución N 172-2013-SUNARP-SN que aprobó la Directiva Nº7-2013-SUNARP-SN, la cual regula la inscripción de los actos y derechos de las instituciones de la Iglesia católica. Esta norma considera que, si bien las instituciones de la Iglesia de carácter público no requieren del registro para gozar de personería jurídica, podrán solicitar, facultativamente, su inscripción en el mismo para contar con los beneficios que brinda la publicidad registral (legitimación, cognoscibilidad general, oponibilidad y Fe Pública Registral). Entonces, esta inscripción tiene carácter declarativo, en tanto dichas instituciones ya cuentan con personería jurídica reconocida por la ley (Decreto Ley $\left.N^{\circ} 23211\right)$. Asimismo, sobre las instituciones que pueden organizarse como asociaciones, esta Directiva precisa que podrán hacerlo, conforme al Código Civil peruano, a partir del momento de su inscripción en el registro civil, sin dejar de respetar su régimen canónico interno.

\subsection{Régimen fiscal}

Los artículos VIII y X del Acuerdo tratan, respectivamente, sobre el sistema de subvenciones para la Iglesia; y las exoneraciones, beneficios tributarios y franquicias que les otorgan las normas legales vigentes. Sabiendo esto, la octava cláusula se expresa de la siguiente forma:

Artículo VIII.- El sistema de subvenciones para las personas, obras y servicios de la Iglesia Católica seguirá como hasta ahora. Las asignaciones personales no tienen el carácter 
ISSN 0719-7160

de sueldo ni de honorarios, por tanto, no constituyen renta sujeta a tributación.

Como se observa, este artículo hace referencia a la continuidad de las subvenciones que recibían las personas, obras y servicios de la Iglesia católica desde antes de la suscripción del Acuerdo; precisando que las asignaciones personales no tienen carácter de sueldo ni de honorarios, por lo que no están sujetas al impuesto a la renta. Esta disposición alcanza a la retribución estatal que los arzobispos, obispos y canónigos reciben a modo de sueldo en el presupuesto de la República ${ }^{5}$. Con esta financiación directa, el Estado busca cubrir los gastos esenciales de la Iglesia, algo que no hace con las restantes confesiones presentes en el territorio nacional.

Sobre el particular, consideramos que esta disposición atenta directamente contra el principio de igualdad religiosa en materia económica, y contra el de neutralidad estatal. Esta asignación directa, basada en un criterio histórico descontinuado, afecta la igualdad de oportunidades de forma sistemática, perjudicando al pluralismo religioso que caracteriza al Perú de hoy. En todo caso, no estamos de acuerdo con la financiación estatal directa de ninguna religión en virtud del principio de laicidad; más bien, sí consideramos permisible el sistema de beneficios y exoneraciones tributarias para todas las confesiones, siempre que se traten de actividades o materias dirigidas a garantizar la libertad religiosa individual y colectiva de los ciudadanos.

Sin perjuicio de ello, junto a este régimen de asignación directa o dotación por parte del Estado, la Iglesia también cuenta con la capacidad de financiación propia, ya que puede recibir donaciones de sus fieles, realizar colectas, o definir el modo que le resulte más conveniente para alcanzar este fin. Adicionalmente, el Estado también ayuda a financiar a la Iglesia por vías indirectas, como dejando a las asignaciones personales fuera de la sujeción del impuesto a la renta, y como las que se establecen en base al artículo X del Acuerdo.

Artículo X.- La Iglesia Católica y las jurisdicciones y comunidades religiosas que la integran continuarán gozando de las exoneraciones y beneficios tributarios y franquicias que les otorgan las leyes y normas legales vigentes ${ }^{6}$.

\footnotetext{
${ }^{5}$ Asimismo, todos los arzobispos, obispos y el obispo castrense, en situación de retiro, reciben pensiones de jubilación vitalicias e intransferibles, de acuerdo al Decreto Ley N 19642.

${ }^{6}$ En 1990, el Estado peruano, mediante el Decreto Legislativo N626, confirmó la vigencia, para todos sus
} 
Diego Alonso Estela Vargas: Breve comparación entre el régimen normativo de colaboración del Estado peruano con la iglesia católica y el aplicable al resto de confesiones religiosas.

Básicamente, esta disposición establece la no sujeción y las exenciones de los sujetos del régimen fiscal de la Iglesia en el Perú. La no sujeción supone que la propia ley tributaria declare que los supuestos afectados quedan fuera de su ámbito y, en consecuencia, no sólo no den lugar al pago de las deudas tributarias correspondientes, sino que tampoco le sean de aplicación las demás obligaciones que pueden establecerse en ellas, como las de carácter formal. De modo que, los autores de actos no sujetos tributariamente no están obligados a presentar declaraciones por los mismos, a registrar sus operaciones, o a someterse a operaciones de control o comprobaciones.

De acuerdo a Rodríguez (2006), la Iglesia católica en el Perú es inafecta, o no está sujeta, en las actividades que son de su propia naturaleza, por lo que no puede quedar sometida respecto a ninguna obligación tributaria derivada de las acciones citadas. No obstante, al momento de realizar sus actos propios debe cumplir los requisitos formales establecidos normativamente por el Estado (pp. 296-297).

Por otro lado, las exenciones tributarias suponen que, si bien los actos exentos o exonerados reúnen los requisitos para ser gravados, por razones especiales, la ley los excluye de tributación. A la fecha, el Estado peruano reconoce a la Iglesia católica, y a sus instituciones precisadas en el artículo $X$, exenciones o exoneraciones correspondientes a los siguientes tributos: Impuesto General a las Ventas (IGV) e Impuesto Selectivo al Consumo; Impuesto a la Renta; Impuesto Predial a los templos, conventos, monasterios y museos; Impuesto al Patrimonio Vehicular; Impuesto de Alcabala. Asimismo, está establecida la inafectación del pago de derechos arancelarios a las donaciones que reciban; y tampoco está gravado con el IGV la importación de los bienes donados a su favor, ni los pasajes internacionales adquiridos para sus agentes pastorales. Finalmente, también están exonerados del pago de los arbitrios municipales relacionados con los predios de su propiedad en los que desarrollen actividades propias ${ }^{7}$.

Precisamente, los sujetos exonerados en virtud de la citada disposición son la Iglesia

efectos, de las exoneraciones, beneficios tributarios y franquicias a favor de la Iglesia Católica, sus jurisdicciones y las comunidades religiosas que las integran de conformidad al Acuerdo de 1980.

${ }^{7}$ Generalmente, estos son los arbitrios de barrido de calles, recolección de residuos sólidos, parques y jardines, y serenazgo. 
católica y todas sus instituciones derivadas que cuentan con personería jurídica pública en el Perú. Por el contrario, las asociaciones y entidades religiosas no comprendidas en el Acuerdo, vale decir, aquellas a las que no se les reconoce personería jurídica pública, deben adecuarse conforme al régimen fiscal general establecido por el Estado peruano.

De esta manera, la Iglesia en el Perú, dentro del marco jurídico dispuesto por el Acuerdo, es tratada por el Derecho Tributario como persona jurídica inafecta en los asuntos propios e inherentes a su naturaleza, respondiendo al principio de autonomía e independencia; y exonerada en aquellos otros que derivan de sus actividades propias.

\subsection{Asistencia religiosa}

La asistencia religiosa ofertada por la Iglesia católica está regulada en el Acuerdo de modo completo y específico para el caso de las Fuerzas Armadas y Policiales, de los centros sanitarios y de los establecimientos penitenciarios. En primer lugar, revisaremos lo dispuesto para las Fuerzas Armadas y Policiales.

De esta manera, el artículo XI del Acuerdo precisa lo siguiente:

Artículo XI.- Consideradas las creencias religiosas de la mayoría nacional, el Estado continúa garantizando que se preste por parte del Vicariato Castrense la asistencia religiosa a los miembros de la Fuerza Armada, Fuerzas Policiales y a los servidores civiles de aquellos que sean católicos.

Sumado a ello, en virtud del artículo XIII, ni el Vicariato Castrense, ni los capellanes dependientes de él, tendrán asimilación a grado militar ni a la jerarquía policial. Sin embargo, al Vicario Castrense le reconocerán las prerrogativas propias de un General de Brigada, y a los capellanes las de un Capitán o su equivalencia, según el Instituto Armado o Policial en el que sirvieren ${ }^{8}$. Asimismo, también tienen derecho a promociones similares a las de los empleados civiles de los Institutos Armados o Policiales ${ }^{9}$.

\footnotetext{
${ }^{8}$ Es decir, si bien el Vicario Castrense y los capellanes no tienen, formalmente, los títulos de esos grados militares o policiales, sí los ostentan materialmente, pues gozan de los beneficios económicos que éstos otorgan. Sobre el particular, Revilla considera que esto vulnera el principio de laicidad (Revilla, 2013, p. 65).

${ }^{9}$ Artículo XIV del Acuerdo suscrito entre el Estado peruano y la Santa Sede de 1980.
} 
Diego Alonso Estela Vargas: Breve comparación entre el régimen normativo de colaboración del Estado peruano con la iglesia católica y el aplicable al resto de confesiones religiosas.

Ahora bien, el artículo XV del Acuerdo añade que el Vicario Castrense tiene que ser peruano de nacimiento y, por razón de su condición episcopal, será nombrado por la Santa Sede de acuerdo con el presidente de la República. A su vez, los capellanes castrenses "por su condición de sacerdotes, serán nombrados por el Vicario Castrense, y reconocidos por los Comandos Generales de los Institutos Armados y Direcciones Superiores de los Institutos Policiales"10. Adicionalmente, la cláusula XVII señala que "los Capellanes Castrenses, en lo posible, serán tomados del Clero de la Diócesis en cuyo territorio se encuentra la Unidad Militar en la que prestarán servicios, y los cambios de colocación se harán previo acuerdo del Vicario Castrense con el Obispo del lugar para su posterior presentación a los Comandos Generales o Direcciones Superiores".

Sobre el particular, Huaco (2005) valora lo siguiente:

Es evidente que el Acuerdo fomenta un modelo de integración ${ }^{11}$, que vulnera el principio de laicidad del Estado y constituye una flagrante demostración de confesionalidad estatal, al procurar para los Vicarios Castrenses la conservación de prerrogativas y derechos que sólo son propios del estatus de la oficialidad y de servidores civiles de los institutos armados o policiales en tanto pertenecen al sector público, y al permitir la intervención del Presidente de la República en asuntos eclesiásticos internos en los que no debería tener nada que ver, como en el nombramiento de los ministros religiosos castrenses (p. 254).

En tal sentido, la cooperación del Estado dirigida a facilitar el culto de los miembros de las Fuerzas Armadas no debería considerar a la asistencia religiosa como una función estatal más, lo cual se consigue al asimilar a los ministros religiosos católicos al régimen público del servicio militar.

Por otro lado, con el fin desarrollar positivamente la prestación de la asistencia

\footnotetext{
${ }^{10}$ Artículo XVI del Acuerdo suscrito entre el Estado peruano y la Santa Sede de 1980.

${ }^{11}$ Doctrinariamente, de acuerdo a este modelo, los servicios de asistencia religiosa se constituyen en servicios públicos de infraestructura y apoyo a la prestación de asistencia espiritual por los ministros de las respectivas confesiones. De esta forma, se establecen cuerpos de capellanes con carácter de funcionarios públicos. Un sistema de este tipo puede resultar poco adecuado si se pretende respetar el principio de autonomía e independencia del poder estatal frente al religioso, y viceversa. Si se desea preservar esta autonomía, debería optarse por un sistema que no suponga tanta vinculación y control por parte del Estado, pues, de no ser así, se corre el peligro de vulnerar la laicidad del Estado.
} 
ISSN 0719-7160

religiosa católica a los militares y policías, se aprobó el Decreto Supremo Nº59-DE/SG, Reglamento del Obispado Castrense del Perú. De esta forma, la tradición confesional católica ha permitido en el Perú una regulación normativa completa de la asistencia religiosa para los fieles católicos pertenecientes a las Fuerzas Armadas y Policiales.

En segundo lugar, respecto a la asistencia religiosa en los centros sanitarios y en los establecimientos penitenciarios, el artículo XVIII del Acuerdo establece lo siguiente:

Artículo XVIII.- El Estado garantiza que se preste asistencia religiosa a los católicos internados en los centros sanitarios y de tutela a su cargo, así como en los establecimientos penitenciarios. Para el ejercicio de las Capellanías de tales obras y centros, se requiere contar con nombramiento Eclesiástico sin que sea exigible el requisito de nacionalidad. Efectuando éste, será presentado a la autoridad competente para los efectos subsiguientes. Los Capellanes forman parte del Servicio Civil del Estado, con todos los derechos y obligaciones, incluida la Seguridad Social.

En virtud de esta disposición, se compromete al Estado a garantizar que se preste asistencia religiosa a los católicos internados en centros sanitarios y en otros de tutela a su cargo, así como en establecimientos penitenciarios. Según Huaco (2005), este artículo plantea un modelo de integración (pp. 259-260); aunque, para otros autores, con el Acuerdo se pasó del modelo de integración orgánica a uno de cooperación (Arrebola, 2014, p. 277) o concertación $^{12}$.

Sobre el particular, llama la atención que el estatuto con el que se considera a los capellanes sea el de capellanes del "Servicio Civil del Estado". Parece que esto es contrario a la igualdad de trato con los ministros de otras confesiones y al principio de laicidad, ya que los capellanes que forman parte de este servicio gozan de todos los derechos que tal situación comporta; de esta manera, su asignación económica corre a cargo del Estado, ventaja que no tiene alguna otra confesión religiosa en el Perú.

\footnotetext{
12 Doctrinariamente, este sistema funciona a través del convenio entre la institución civil correspondiente y la confesión religiosa acerca de la aportación de recursos humanos y materiales por una y otra parte. Tal acuerdo es lo que dota de legitimidad a la cooperación que se establece entre el Estado y la confesión religiosa y, además de aportar seguridad jurídica al sistema, ofrece, en este caso, continuidad asistencial según las necesidades de cada centro.
} 
Diego Alonso Estela Vargas: Breve comparación entre el régimen normativo de colaboración del Estado peruano con la iglesia católica y el aplicable al resto de confesiones religiosas.

Finalmente, la asistencia religiosa en los centros sanitarios y en los establecimientos penitenciarios ha sido desarrollada jurídicamente a través de normas comunes, las cuales son aplicables a todas las confesiones religiosas situadas en el territorio peruano.

\section{La Ley de Libertad Religiosa y su reglamento}

A continuación, examinaremos la situación jurídica de las confesiones no católicas, estudiando la regulación determinada por la Ley de Libertad Religiosa ${ }^{13}$ (Ley N²9635) y su reglamento vigente ${ }^{14}$ (Decreto Supremo N006-2016-JUS).

Siendo así, la Ley de Libertad Religiosa es una norma de derecho interno, con rango infraconstitucional, que representa una fuente unilateral de Derecho Eclesiástico. Está conformada por quince artículos, cuatro disposiciones complementarias y finales, y una disposición complementaria transitoria. Básicamente, desarrolla un derecho fundamental de sustento constitucional directo. Se trata de una ley ordinaria, no orgánica, por lo que no forma parte del bloque de constitucionalidad.

Los asuntos que, principalmente, se tratan en esta norma y en su reglamento son los siguientes: los derechos del ejercicio individual de la libertad religiosa, el concepto de entidad religiosa, y los derechos de las entidades religiosas inscritas en el registro. Sin embargo, también resaltan otros temas que, si bien no han sido muy desarrollados, son relevantes para el presente trabajo, como el caso de la asistencia religiosa.

Ahora, si bien esta ley fue promulgada para reparar la desigualdad y la omisión en la regulación del régimen de las confesiones no católicas, consideramos que no equipara del todo a las confesiones minoritarias con la Iglesia católica en cuanto a igualdad de trato y oportunidades, como se verá seguidamente.

\subsection{Asistencia religiosa}

\footnotetext{
13 Publicada el 21 de diciembre de 2010.

14 Publicado el 19 julio 2016.
} 
El artículo $3^{\circ}$ de la mencionada ley regula el ejercicio individual de los derechos relacionados con la libertad de religión. Así, en el epígrafe c) de esta disposición, se hace referencia a la asistencia religiosa de la siguiente forma:

Artículo $3^{\circ}$. - Ejercicio individual de la libertad de religión

La libertad de religión comprende, entre otros, el ejercicio de los siguientes derechos:

(...) c. Recibir asistencia religiosa por su confesión. Las instituciones públicas competentes adoptan las medidas y normas necesarias para facilitar la asistencia religiosa en el ámbito de las Fuerzas Armadas y de la Policía Nacional del Perú, en las prisiones, en los centros públicos hospitalarios, asistenciales y otros bajo su dependencia. (...) $)^{15}$

La asistencia religiosa es una manifestación del derecho fundamental de libertad religiosa que requiere de la cooperación por parte de los poderes públicos para que sea realmente efectiva en el caso de las personas que tienen disminuidas las posibilidades de recibirla por encontrarse en centros caracterizados por un régimen especial de sujeción, ya sea en el ámbito de las Fuerzas Armadas y de la Policía Nacional del Perú, en las prisiones, en los centros públicos hospitalarios y asistenciales, etc.

Por esta disposición, entendemos que el Estado se encuentra en la obligación de facilitar a las entidades religiosas la asistencia espiritual en favor del personal sujeto a las dependencias públicas señaladas, adoptando, para tal fin, las medidas necesarias ya sea, mediante la formalización de normas internas unilaterales como directivas, autorizaciones, permisos escritos, o por medio de acuerdos de orden mutuo o sinalagmático, como los convenios de cooperación. Todos estos instrumentos de carácter formal se condicen con la función pública de los diferentes niveles del Estado, los cuales deben promover el ejercicio de este derecho.

Al respecto, el artículo $6^{\circ}$ del reglamento de la ley precisa lo siguiente:

Artículo $6^{\circ}$. - Asistencia religiosa

\footnotetext{
${ }^{15}$ Complementariamente, el literal c) del artículo $9^{\circ}$ de la Ley de Libertad Religiosa establece que nadie puede ser obligado a recibir asistencia religiosa.
} 
Diego Alonso Estela Vargas: Breve comparación entre el régimen normativo de colaboración del Estado peruano con la iglesia católica y el aplicable al resto de confesiones religiosas.

La asistencia religiosa en las instituciones públicas indicadas en el artículo $3^{\circ}$ de la Ley se dispensa por los ministros de culto o agentes pastorales designados por las entidades religiosas.

Los ministros de culto o agentes pastorales se identifican con la credencial emitida por la autoridad de la entidad religiosa a la que pertenecen, la misma que es renovada anualmente para efecto de facilitar la asistencia religiosa a la que se refiere la Ley.

Las Fuerzas Armadas y la Policía Nacional del Perú pueden establecer mecanismos administrativos que les permita contar con ministros de culto o agentes pastorales de las entidades religiosas, los que debidamente identificados, brinden asistencia religiosa a sus miembros.

Por cómo se expresa este artículo, creemos que el régimen general establecido para la asistencia religiosa en los sitios mencionados en el artículo $3^{\circ}$ de la ley es el de libre acceso, el cual consiste, valga la redundancia, en el libre acceso de los ministros religiosos al interior de estos centros. De esta forma, parece que la única condición que se exige para la prestación de este servicio espiritual es que los ministros de culto o agentes pastorales que la dispensen se identifiquen con una credencial emitida por la autoridad de la entidad religiosa a la que pertenecen. Consideramos que este requisito tiene la finalidad de garantizar el orden y la seguridad en el interior de estos lugares, lo cual parece correcto.

Asimismo, resulta acertado que esta disposición no solo haga referencia a los ministros de culto como los únicos responsables de realizar la asistencia religiosa, sino también a los agentes pastorales, debido a que, en algunos casos, quien asiste espiritualmente a los internos no es necesariamente un ministro espiritual, sino alguna otra persona que pertenece a su comunidad religiosa, la que también podría prestar servicios y apoyo de este tipo, siempre y cuando esté debidamente identificada bajo los términos precisados. Esta fórmula preserva mejor la libertad religiosa de los individuos en situación de sujeción.

Ahora bien, en el ámbito de las Fuerzas Armadas y de la Policía Nacional del Perú, así como en el público hospitalario y asistencial, no existe mayor elaboración normativa que la 
dispuesta por la Ley de libertad religiosa y su reglamento acerca de la asistencia religiosa. No obstante, la asistencia espiritual en el ámbito penitenciario cuenta con una extensión normativa bastante completa ${ }^{16}$. En palabras de Huaco (2005), "es en este terreno donde el ordenamiento jurídico peruano ha tenido más en cuenta el principio de igualdad religiosa y de cooperación, además de otorgar plena libertad religiosa al regular normativamente la asistencia religiosa y el ejercicio del culto al interior de los establecimientos penitenciarios" (p. 258).

En conclusión, sobre el régimen normativo de asistencia religiosa en el Perú, podemos afirmar que para las confesiones religiosas no católicas existe, básicamente, un modelo de libertad de acceso de los representantes religiosos en el ámbito de las Fuerzas Armadas y de la Policía Nacional, en las prisiones, en los centros públicos hospitalarios y asistenciales, y en todo otro sitio bajo dependencia del Estado; sin perjuicio de contar con la posibilidad de suscribir acuerdos de orden mutuo sobre esta materia. Por el contrario, la Iglesia católica se maneja bajo un modelo de integración o de concertación en estos ambientes.

\subsection{Personalidad jurídica y registro}

Referirnos a la personalidad jurídica de las entidades religiosas supone entender primero que éstas tienen capacidad jurídica civil ${ }^{17}$ para ser titular de derechos y deberes y, consecuentemente, para actuar como sujeto de derecho en el tráfico jurídico. Este es el tenor del artículo $13^{\circ}$ de la ley:

Artículo $13^{\circ}$. - Registro de Entidades Religiosas

A partir de la vigencia de la presente Ley, el registro creado en el Ministerio de Justicia por Decreto Supremo N003-2003-JUS pasa a denominarse Registro de Entidades Religiosas y tiene como finalidad principal el reconocimiento de la personería jurídica civil de las

\footnotetext{
${ }^{16}$ Véanse los artículos $93^{\circ}, 94^{\circ}$ y $102^{\circ}$ del Código de Ejecución Penal, aprobado por el Decreto Legislativo $N^{\circ}$ 654; y los artículos $147^{\circ}$ al $151^{\circ}$ del reglamento del Código de Ejecución Penal, aprobado por el Decreto Supremo $N^{\circ} 015-2003-J U S$.

${ }^{17}$ La personalidad jurídica civil está dispuesta para todas las entidades religiosas no católicas en el Perú, pues, como se observó anteriormente, la Iglesia católica y sus instituciones eclesiásticas derivadas tienen un régimen de personería jurídica especial en virtud del Acuerdo con la Santa Sede de 1980.
} 
Diego Alonso Estela Vargas: Breve comparación entre el régimen normativo de colaboración del Estado peruano con la iglesia católica y el aplicable al resto de confesiones religiosas.

entidades religiosas, así como facilitar sus relaciones con el Estado.

La inscripción en el mencionado registro es voluntaria.

Las entidades religiosas inscritas son personas jurídicas de derecho privado sin fines de lucro. Su organización, funciones, atribuciones y representación se rigen por esta Ley y su reglamento, así como por sus propias normas y estatutos.

Las entidades religiosas no inscritas en el registro continúan como asociaciones civiles.

Desde el año 2003, el Perú cuenta con un registro de confesiones religiosas no católicas, denominado actualmente: "Registro de Entidades Religiosas", el cual está a cargo, hoy en día, del Ministerio de Justicia y Derechos Humanos. Es decir, al momento de la entrada en vigencia de la Ley de Libertad Religiosa, ya existía un registro ${ }^{18}$ y algunas confesiones religiosas inscritas; realidad que se reconoce en el primer párrafo de la disposición citada ${ }^{19}$.

El mandato de este artículo parece claro y concreto: el Registro de Entidades Religiosas tiene como finalidades principales facilitar las relaciones del Estado con las confesiones religiosas distintas a la católica y reconocer la personería jurídica civil de las mismas. Asimismo, indica que la inscripción en el registro es voluntaria, por lo que las entidades no inscritas en el mismo continúan como asociaciones civiles.

Sin embargo, académicamente se ha discutido si la naturaleza de la inscripción en el Registro de Entidades Religiosas es constitutiva o no. No obstante, la interpretación oficial del Estado, a través del Ministerio de Justicia y Derechos Humanos, es que las entidades religiosas en el Perú, de acuerdo con el Código Civil, se rigen por sus propios estatutos aprobados por su autoridad eclesiástica, por lo que, para obtener personería jurídica civil, se

\footnotetext{
${ }^{18}$ Éste se denominaba "Registro de confesiones religiosas distintas a la católica".

${ }^{19}$ La Única Disposición Complementaria Transitoria de la Ley de Libertad Religiosa estableció un plazo de trescientos sesenta (360) días útiles para que las entidades religiosas, que se habían inscrito bajo el Decreto Supremo N 003-2003-JUS, se reinscribieran; de lo contrario, se procedería a su cancelación. Este plazo venció el 18 de enero de 2013. A la fecha, existen 127 entidades religiosas registradas, de acuerdo a la página web del Ministerio de Justicia y Derechos Humanos: https://www.minjus.gob.pe/registro-nacional-de-confesiones-yentidades-religiosas/.
} 
ISSN 0719-7160

deben inscribir como asociaciones civiles en Registros Públicos. En virtud de ello, si voluntariamente deciden solicitar su inscripción en el registro a cargo del mencionado Ministerio, previamente deberán contar con estatutos elevados a Registros Públicos y cumplir con los requisitos administrativos para tal efecto. Entonces, el Registro de Entidades Religiosas es voluntario, administrativo y no constitutivo ${ }^{20}$.

Por otro lado, el artículo $12^{\circ}$ del reglamento de la ley apunta lo siguiente:

Artículo $12^{\circ}$. - Registro de Entidades Religiosas

La inscripción en el Registro de Entidades Religiosas a que se refiere el artículo $13^{\circ}$ de la Ley, es voluntaria y está a cargo del Ministerio de Justicia y Derechos Humanos. Tiene una vigencia de tres (03) años y es renovable.

En el marco del artículo $13^{\circ}$ de la Ley, el Registro facilita las relaciones del Estado con las entidades religiosas, lo que permite la simplificación administrativa respecto de los beneficios que las entidades públicas les otorgan en el marco del ordenamiento jurídico.

Las entidades religiosas que no se inscriban en el Registro de Entidades Religiosas, se identifican como tales con sus Estatutos que contengan fines religiosos inscritos en Registros Públicos.

Al respecto, por lo establecido en este artículo, se puede concluir categóricamente que el Registro de Entidades Religiosas no está diseñado para atribuir personería jurídica a las entidades religiosas, sino que la inscripción en el mismo sólo se trata de un acto administrativo voluntario, cuya finalidad es facilitar las relaciones del Estado con las entidades religiosas y permitir la simplificación administrativa respecto de los beneficios que les otorgan en el marco del ordenamiento jurídico.

Se estatuye, entonces, un reconocimiento especial a nivel administrativo que identifica a la iglesia, confesión o comunidad inscrita como entidad religiosa propiamente dicha, y que resulta oponible ante cualquier autoridad a los efectos de acreditar tal

\footnotetext{
${ }^{20}$ Véase: Ministerio de Justicia y Derechos Humanos. Reporte de: La Libertad Religiosa en el Perú y el Registro de Entidades Religiosas, Lima, 2016: https://www.minjus.gob.pe/wp-content/uploads/2016/10/Cartilla-LaLibertad-Religiosa-en-el- Per\%C3\%BA-y-el-Registro-de-Entidades-Religiosas.pdf.
} 
Diego Alonso Estela Vargas: Breve comparación entre el régimen normativo de colaboración del Estado peruano con la iglesia católica y el aplicable al resto de confesiones religiosas.

condición, lo cual, en buena cuenta, traduce una postura estatal de certeza y seguridad de las condiciones del sujeto colectivo religioso al que se está reconociendo, lo que implementa la cooperación con el poder público.

Teniendo ello en cuenta, el artículo $14^{\circ}$ de la ley indica los requisitos para la inscripción de las entidades religiosas:

Artículo $14^{\circ}$. - Requisitos para inscripción de entidades religiosas

Para inscribirse en el Registro de Entidades Religiosas, se presenta una solicitud en la que consta fehacientemente lo siguiente:

a. Su fundación o establecimiento en el Perú, con indicación del número de fieles mayores de edad, lugares de culto y cuantos datos se consideren relevantes a efectos de poner de manifiesto su implantación.

b. Su denominación y demás datos de identificación, los estatutos donde se señalen sus bases de fe, actividades religiosas, régimen de funcionamiento, esquema de organización y órganos representativos con expresión de sus facultades y de los requisitos para su válida designación.

Tienen acceso al registro aquellas entidades religiosas que, por su trayectoria, ámbito, número de creyentes y/o desarrollo de actividades benéfico-asistenciales o educativas, ofrecen garantías de estabilidad y permanencia.

La inscripción requiere prueba, por cualquier medio admitido en derecho, del ejercicio constante de actividades religiosas propias, que determine la creación, fundación y presencia activa de la confesión en el Perú, por un período no menor de siete (7) años, así como de un número de fieles, mayores de edad, no inferior a lo que determine el reglamento.

La inscripción en el registro conlleva el reconocimiento de la personería jurídica, que se otorga cuando se acreditan debidamente los requisitos exigidos y no se vulnera algunos de los preceptos de la presente Ley o del ordenamiento jurídico general. 
La denegación de la inscripción no impide su actuación en el marco de las libertades reconocidas en la Constitución Política del Perú ni el ejercicio de los derechos que se reconocen en la presente Ley.

La cancelación de los asientos relativos a una determinada entidad religiosa solo puede llevarse a cabo a petición de sus representantes legales, debidamente facultados, o mediante resolución judicial.

Los requisitos señalados en esta disposición buscan asegurar que lo que se inscriba sea una verdadera entidad religiosa y no un mero proyecto religioso; en tal sentido, se solicitan datos relacionados con su identificación, así como aquellos que acreditarían su naturaleza religiosa. Adicionalmente, se establece que sólo tendrán acceso al registro las entidades que ofrezcan garantías de estabilidad y permanencia. Por lo tanto, se requiere prueba del ejercicio constante de actividades religiosas propias por un período no menor de siete años, así como de un número de fieles mayores de edad no inferior a lo que determina el reglamento.

Sobre el particular, el artículo $13^{\circ}$ del reglamento precisa lo siguiente:

Artículo $13^{\circ}$. - Requisitos para la inscripción en el Registro de Entidades Religiosas

El procedimiento de inscripción en el Registro de Entidades Religiosas se inicia con la presentación de una solicitud con firma del representante de la entidad, debidamente legalizada por notario público, acompañando la siguiente información y documentación:

a) Denominación de la entidad;

b) Domicilio real en el territorio nacional;

c) Descripción de su credo, base doctrinal y textos o libros sagrados;

d) Declaración Jurada de no desarrollar las actividades a que se refiere el segundo párrafo del artículo $5^{\circ}$ de la Ley, firmada por quien suscribió la solicitud de inscripción;

e) Descripción de su organización e historia, que permitan apreciar el ejercicio de actividades religiosas propias, y que determine con exactitud la creación, fundación y 
Diego Alonso Estela Vargas: Breve comparación entre el régimen normativo de colaboración del Estado peruano con la iglesia católica y el aplicable al resto de confesiones religiosas.

presencia activa de la entidad religiosa en el Perú, por un período no menor de siete (07) años, lo que garantiza su estabilidad y permanencia en el territorio nacional;

f) Mención del número de fieles mayores de edad con el que cuente en el territorio nacional, el cual no será menor de quinientos (500), salvo que se trate de confesión religiosa histórica;

g) Relación de sus ministros de culto y religiosos, según el caso;

h) Relación y domicilio real de templos o lugares de culto y casas religiosas, centros de educación teológica y formación religiosa, colegios y otras sedes o dependencias, si los tuviere;

i) Copia de los estatutos donde se señalen sus fines religiosos, bases doctrinales o de fe y la estructura eclesiástica o confesional, esquema de organización y órganos representativos con expresión de sus facultades y de los requisitos para su válida designación;

j) Copia legalizada o autenticada por fedatario, del testimonio de la escritura pública de constitución como asociación y de la certificación de inscripción vigente en los Registros Públicos;

j) Certificado de Vigencia de Poder del representante.

La Declaración Jurada, y toda información declarativa, están sujetas a las consecuencias de orden civil, administrativo y penal, conforme lo establece el artículo $427^{\circ}$ del Código Penal, en concordancia con el "Principio de Presunción de Veracidad", previsto en el inciso 1.7) del Artículo IV de la Ley N²7444, Ley del Procedimiento Administrativo General.

Desde nuestro punto de vista, si bien creemos que la exigencia de un número mínimo de fieles es un requisito cuestionable, consideramos que la cifra contemplada en el 
reglamento vigente es mejor que la anterior ${ }^{21}$, pues refleja un mayor conocimiento de la realidad peruana actual y, consecuentemente, facilita las relaciones del Estado con las entidades religiosas, lo que se traduce en la simplificación administrativa respecto de los beneficios que las entidades públicas les otorgan en el marco del ordenamiento jurídico.

Por último, solo resta decir que, de acuerdo a la Tercera Disposición Complementaria Final del reglamento de la ley, el Registro de Entidades Religiosas cuenta con una sección especial para la inscripción de las comunidades religiosas conocidas como "organizaciones misioneras", las cuales cuentan en sus estatutos con fines asistenciales ${ }^{22}$.

\subsection{Beneficios tributarios}

El artículo $11^{\circ}$ de la ley hace referencia al tema de las donaciones y beneficios tributarios a favor de las entidades religiosas de la siguiente forma:

Artículo $11^{\circ}$. - Donaciones y beneficios tributarios

Las entidades religiosas gozan de las donaciones y beneficios tributarios existentes siempre que cumplan con los requisitos previstos en el ordenamiento jurídico nacional.

Como se puede observar, esta norma no explica el régimen tributario aplicable a las entidades religiosas, sino simplemente precisa que pueden recibir donaciones y que gozan de los beneficios tributarios establecidos en el ordenamiento jurídico siempre que cumplan con los requisitos previstos. Asimismo, el reglamento de la ley no específica nada acerca de ello tampoco; más bien, tan solo indica que las entidades religiosas gozan de capacidad y libertad para la adquisición y disposición de bienes, así como para recibir donaciones internas y externas conforme a lo establecido en sus propios estatutos y en el ordenamiento jurídico vigente ${ }^{23}$.

Tanto la ley, como el reglamento, omiten la obligación de inscripción en el Registro de Entidades Religiosas para que las mismas puedan gozar, efectivamente, de los beneficios

\footnotetext{
${ }^{21}$ El anterior reglamento de la ley fijaba la cantidad de diez mil (10.000) fieles o adherentes mayores de edad.

${ }^{22}$ A la fecha, existen 16 organizaciones misioneras registradas, de acuerdo a la página web del Ministerio de Justicia y Derechos Humanos: https://www.minjus.gob.pe/registro-nacional-de-confesiones-y-entidadesreligiosas/.

${ }^{23} \mathrm{Cfr}$. Artículo $11^{\circ}$ del reglamento de la Ley de Libertad Religiosa.
} 
Diego Alonso Estela Vargas: Breve comparación entre el régimen normativo de colaboración del Estado peruano con la iglesia católica y el aplicable al resto de confesiones religiosas.

tributarios establecidos en las normas correspondientes. En tal sentido, no es necesaria esta inscripción administrativa para que gocen de los favores fiscales dispuestos por el Estado ${ }^{24}$.

Actualmente, los beneficios fiscales que gozan las entidades religiosas no católicas en el Perú no se diferencian mucho de los otorgados a la Iglesia católica ${ }^{25}$ y a sus instituciones derivadas. En esta línea, se distinguen las exenciones o exoneraciones correspondientes a los siguientes tributos: Impuesto General a las Ventas (IGV) e Impuesto Selectivo al Consumo; Impuesto a la Renta; Impuesto Predial a los templos, conventos, monasterios y museos; Impuesto al Patrimonio Vehicular; e Impuesto de Alcabala. Asimismo, está establecida la inafectación del pago de derechos arancelarios a las donaciones que reciban, y tampoco está gravado con el IGV la importación de los bienes donados a su favor.

\section{CONCLUSIONES}

La Ley de Libertad Religiosa fue promulgada para reparar la desigualdad y la omisión en la regulación del régimen de las confesiones no católicas; empero, consideramos que esta norma no equipara del todo a las confesiones minoritarias con la Iglesia católica, con respecto a lo establecido en el Acuerdo de 1980, en cuanto a igualdad de trato y oportunidades.

Sobre el régimen normativo de asistencia religiosa, podemos afirmar que para las confesiones religiosas no católicas existe, básicamente, un modelo de libertad de acceso de los representantes religiosos en el ámbito de las Fuerzas Armadas y de la Policía Nacional, en las prisiones, en los centros públicos hospitalarios y asistenciales, y en todo otro sitio bajo dependencia del Estado; sin perjuicio de contar con la posibilidad de suscribir acuerdos de orden mutuo sobre esta materia. Por el contrario, la Iglesia católica se maneja bajo un modelo de integración o de concertación en estos ambientes.

\footnotetext{
${ }^{24}$ Sin perjuicio de ello, cabe recordar que, de acuerdo al artículo $12^{\circ}$ del reglamento de la ley, el Registro de Entidades Religiosas permite la simplificación administrativa respecto de los beneficios que las entidades públicas les otorgan en el marco del ordenamiento jurídico.

${ }^{25}$ A diferencia de las entidades religiosas no católicas, la Iglesia católica no está gravada con el IGV en el caso de los pasajes internacionales adquiridos para sus agentes pastorales. Asimismo, las entidades no católicas no gozan de las prerrogativas económicas que tienen las autoridades eclesiales católicas respecto a la inafectación tributaria de los sueldos y honorarios que reciben, ni perciben financiación directa del Estado.
} 
Con respecto a la personalidad jurídica, el Acuerdo de 1980 otorga a la Iglesia católica, y a sus instituciones eclesiásticas derivadas, personalidad jurídica pública; por el contrario, las confesiones religiosas no católicas sólo pueden adquirir personalidad jurídica privada o civil.

De esta forma, en cuanto al registro, si bien las instituciones de la Iglesia de carácter público no requieren del mismo para gozar de personería jurídica, podrán solicitar, facultativamente, su inscripción para contar con los beneficios que brinda la publicidad registral. Por otro lado, sobre las entidades religiosas no católicas, si voluntariamente deciden solicitar su inscripción en el Registro de Entidades Religiosas (RER), previamente deberán contar con estatutos elevados a Registros Públicos y cumplir con los requisitos administrativos para tal efecto. Por lo tanto, el RER es voluntario, administrativo y no constitutivo, y tiene como finalidad facilitar las relaciones del Estado con las entidades religiosas, lo que permite la simplificación administrativa respecto de los beneficios que las entidades públicas les otorgan en el marco del ordenamiento jurídico.

Finalmente, acerca del ámbito tributario, los beneficios fiscales que gozan las entidades religiosas no católicas no se diferencian mucho de los otorgados a la Iglesia y a sus instituciones derivadas. No obstante, la Iglesia católica no está gravada con el IGV en el caso de los pasajes internacionales adquiridos para sus agentes pastorales. Asimismo, las entidades no católicas no gozan de las prerrogativas económicas que tienen las autoridades eclesiales católicas respecto a la inafectación tributaria de los sueldos y honorarios que reciben, ni perciben financiación directa del Estado.

\section{REFERENCIAS BIBLIOGRÁFICAS}

ARREBOLA, Ángel. La asistencia religiosa penitenciaria. Comentario a la Sentencia 27002006- PHC/TC. En: DIAZ, Óscar, ETO, Gerardo y FERRER, Javier (coords). El derecho fundamental de libertad religiosa: jurisprudencia y doctrina constitucional. Lima: Tribunal Constitucional del Perú, 2014. ISSN: XXXXXXX

FERNÁNDEZ, Carlos. Derecho de las personas: exposición de motivos y comentarios al libro primero del Código civil peruano. Lima: Studium, 1986. ISSN: XXXXXXXX 
Diego Alonso Estela Vargas: Breve comparación entre el régimen normativo de colaboración del Estado peruano con la iglesia católica y el aplicable al resto de confesiones religiosas.

FLORES, Gonzalo. Principios y criterios para una recta aplicación del Acuerdo Internacional entre la Santa Sede y la República del Perú. En: Congreso Relaciones entre la Iglesia católica y el Estado peruano. Reflexiones y ponencias. Arequipa: Universidad Católica San Pablo, 2007, pp. 49-80. ISSN: 9789972825187

HUACO, Marco. ¿Laicidad o pluriconfecionalidad?: políticas públicas de gestión del pluralismo religioso: Análisis Comparado [en línea]. Tesis de Magíster en Ciencias de la Religión. Lima: Universidad Nacional Mayor de San Marcos. Facultad de Ciencias Sociales, 2010. [consulta: 12 de enero del 2017]. Disponible

en: http://cybertesis.unmsm.edu.pe/bitstream/handle/cybertesis/1370/Huaco_pm.pdf?seque nce $=1 \&$ is Allowed $=y$

HUACO, Marco. Derecho de la religión: el principio y derecho de libertad religiosa en el ordenamiento jurídico peruano. Lima: Universidad Peruana Unión, 2005. ISBN: 9972462919

MINISTERIO DE JUSTICIA Y DERECHOS HUMANOS. La Libertad Religiosa en el Perú y el Registro de Entidades Religiosas [en línea]. Lima, 2016. [consulta: 20 de abril de 2017]. Disponible en: https://www.minjus.gob.pe/wp-content/uploads/2016/10/Cartilla-LaLibertad-Religiosa-en-el- Per\%C3\%BA-y-el-Registro-de-Entidades-Religiosas.pdf.

REVILLA, Milagros A. Derecho eclesiástico del Estado peruano. Lima: Fondo Editorial de la Pontificia Universidad Católica del Perú, 2017. ISBN: 9786123172596

REVILLA, Milagros A. El sistema de relación Iglesia - Estado peruano: los principios rectores del derecho eclesiástico del estado en el ordenamiento jurídico peruano [en línea]. Tesis de magister en Derecho Constitucional. Lima: Pontificia Universidad Católica del Perú. Escuela de Posgrado. 2013. [consulta 16 de junio del

2017]. Disponible en:

http://tesis.pucp.edu.pe/repositorio/bitstream/handle/20.500.12404/4505/REVILLA_IZQUI ERDO_MILAGROS_IGLESIA_ESTADO.pdf?sequence=1\&isAllowed=y

RODRÍGUEZ, Juan. La relevancia jurídica del Acuerdo entre la Santa Sede y el Perú: La 
ISSN 0719-7160

personalidad jurídica de la Iglesia en el Perú y sus implicaciones en el ordenamiento jurídico peruano. Lima: Editorial ROEL SAC, 2006. ISBN: 9972332489

VALDERRAMA, Carlos. El Reglamento de reconocimiento de Asociaciones como entidades no lucrativas con fines educativos. Boletín del Instituto de Derecho Eclesiástico - IDEC. 1998, vol. Año 2, núm. 3, pp. 2-4. ISSN: XXXX-XXXX 